\title{
Análise do comportamento: behaviorismo radical, análise experimental do comportamento e análise aplicada do comportamento ${ }^{1}$
}

\author{
Marcus Bentes de Carvalho Neto \\ Universidade Federal do Pará
}

\begin{abstract}
Resumo
Há diversas práticas culturais envolvidas no que se convencionou chamar de "Psicologia Comportamental" ou simplesmente de "Behaviorismo". O presente trabalho desenvolve o argumento de Tourinho (1999), em favor de uma classificação onde a Análise do Comportamento seria a área mais ampla da prática behaviorista, contendo três subáreas interligadas: o Behaviorismo Radical (uma filosofia), a Análise Experimental do Comportamento (uma ciência básica) e a Análise Aplicada do Comportamento (uma ciência aplicada e uma tecnologia). Descreve-se o que definiria cada uma das subáreas e como elas estariam irremediavelmente relacionadas.

Palavras-chave: behaviorismo; análise do comportamento; psicologia comportamental.
\end{abstract}

\begin{abstract}
Behavior analysis: radical behaviorism, experimental analysis of behavior and applied behavior analysis

There are many cultural practices related to generic terms such as "behavioral psychology" or simply "behaviorism". This paper develops Tourinho's (1999) argument towards a classification where behavior analysis is the large area of behaviorist practice, that comprises three linked sub-areas: radical behaviorism (a philosophy), experimental analysis of behavior (a basic science) and applied behavior analysis (an applied science and a technology). This paper describes these sub-areas and how they are irremediably related.

Keywords: behaviorism; behavior analysis; behavioral psychology.
\end{abstract}

\section{Parte I: A Fundação Oficial do Behaviorismo}

A Psicologia tradicionalmente tem sido descrita como uma ciência da mente, especialmente do que se convencionou chamar de "mente humana". No final do século 19 e início do século 20, a Psicologia Acadêmica predominante era a Introspectiva, na qual os métodos e instrumentos da Fisiologia foram adaptados a alguns dos problemas tradicionais da Filosofia, especialmente em relação à origem do conhecimento humano e à gênese e composição das sensações e percepções sobre o mundo. Wundt e posteriormente Titchener eram seus principais expoentes. Em uma situação controlada de laboratório, os pesquisadores examinavam, através do relato verbal dos sujeitos humanos, qual a estrutura e o modo de interação dos processos conscientes, legítimos objetos de estudo de uma ciência psicológica na época.

Em 1913, J. B. Watson (Watson, 1913/1965) ${ }^{2}$ publica um artigo agora clássico "Psychology As The Behaviorist Views It" ("A Psicologia Como o Behaviorista a Vê"), conhecido hoje como uma espécie de "manifesto behaviorista", no qual explicitamente anuncia o rompimento com a forma de fazer Psicologia até então estabelecida. Divergia em relação ao objeto a ser adotado (substituindo a "consciência" pelo "comportamento dos organismos"), ao método adequado para levar o empreendimento adiante (abandonava a "introspecção" e adotava a experimentação com processos interativos diretamente observáveis entre um organismo e seu ambiente, especialmente os envolvidos na aprendizagem), aos objetivos dessa ciência (que ganhava, então, fortes contornos pragmáticos e partia em busca de um "conhecimento útil", uma tecnologia psicológica, voltada para a previsão e o controle do comportamento), e, obviamente, dos pressupostos sobre o que seria ciência e qual a natureza dos eventos psicológicos (o dualismo, o imaterialismo, mesmo que implícito, da mente era substituído por uma concepção naturalista, monista materialista/fisicalista, objetivista e evolucionista dos eventos psicológicos legítimos, os comportamentais). Watson chamou essa nova Psicologia de "Behaviorismo" (Para maiores detalhes, ver Marx e Hillix, 1963/1993; Broadbent, 1960/1972; Heidbreder, 1933/1975).

Sob o rótulo de "Behaviorismo", Watson empreendeu atividades muito diversas. Estabeleceu uma justificativa filosófica para sua nova Psicologia (como o próprio manifesto de 1913), adotou estratégias de pesquisa empírica, especialmente em 
laboratório, para construir os princípios de uma ciência comportamental, como os trabalhos sobre aquisição de comportamentos de "medo" e de outras atividades emocionais em crianças (Watson, 1924/1958) e criou estratégias de intervenção, derivadas dos princípios científicos do comportamento, como suas seminais técnicas de propaganda (Marcos e Carvalho Neto, 2001).

A chamada escola behaviorista posterior a Watson, "neobehaviorista", com autores como Hull, Tolman, Lashley, Spencer, Guthrie, Boring e Stevens, também manteve uma grande diversidade de atividades sob o mesmo guarda-chuva terminológico. Dessa forma, a palavra "Behaviorismo" poderia designar uma filosofia, um método, uma explicação, uma técnica, um tipo de intervenção e até uma posição política.

\section{Parte II: O Behaviorismo Skinneriano e a Proposta de Classificação de Tourinho (1999)}

$\mathrm{Na}$ década de 30 do século 20, B. F. Skinner iniciou seus trabalhos em Psicologia em duas frentes durante o seu doutoramento: de um lado, realizou uma pesquisa histórica e conceitual sobre a noção de "reflexo" na Fisiologia e na Psicologia (uma tentativa de dar uma roupagem operacional ou estritamente funcional ao termo e adotá-lo como ferramenta explicativa em sua ciência). De outro, criou e adotou recursos metodológicos e técnicos em uma ampla linha de pesquisa experimental em laboratório (as duas facetas são apresentadas de forma clara em Skinner, 1938/1966). Some-se a isso que o interesse de Skinner na Psicologia, como atesta sua própria autobiografia (Skinner, 1979), também foi fortemente marcado pela possibilidade de intervenção social (Andery, 1990), o que fica mais evidente com a publicação de sua novela utópica "Walden II' (Skinner, 1948/1971) e de vários artigos sobre educação (ver Skinner, 1972), que acabaram por conduzi-lo ao seu "Technology of Teaching" ("Tecnologia do Ensino") (Skinner, 1968a).

Note-se, então, que em Skinner também há diferentes modalidades de conhecimento convivendo no mesmo espaço. Em 1945, Skinner (1945) chama a sua versão de Behaviorismo de "Behaviorismo Radical" e o faz especialmente para diferenciar-se do Behaviorismo de Boring e Stevens, a quem chama de behavioristas, apenas, "metodológicos". O Behaviorismo Radical seria a filosofia por trás da Ciência do Comportamento que ele estava tentando erguer e que deveria no futuro substituir a própria Psicologia, profunda e irremediavelmente impregnada por pressupostos mentalistas. Tal ciência foi chamada de "Análise Experimental do Comportamento".

Recentemente, Tourinho (1999) sugeriu uma reorganização terminológica para os diversos saberes behavioristas de tradição skinneriana ${ }^{3}$. De acordo com a sua estrutura, a área ampla seria chamada simplesmente de Análise do Comportamento (AC). O seu braço teórico, filosófico, histórico, seria chamado de Behaviorismo Radical. O braço empírico seria classificado como Análise Experimental do Comportamento. $\mathrm{O}$ braço ligado à criação e administração de recursos de intervenção social seria chamado de Análise Aplicada do Comportamento.

As três subáreas estariam inter-relacionadas em um processo contínuo de alimentação recíproca. Para Tourinho (1999), nenhuma das três existiria de forma autônoma, por mais que, algumas vezes, os seus representantes não consigam identificar claramente seus vínculos com as demais. Assim, mesmo que um pesquisador de laboratório estivesse dedicado ao exame de propriedades de um tipo específico de esquema de reforçamento em pombos, as razões pelas quais: (a) pombos seriam sujeitos legítimos para estudar processos que se tenta compreender em humanos, (b) o comportamento estaria sendo investigado em si mesmo e não como expressão de outro nível de análise (fisiológico, conceitual e mental), (c) o porquê da adoção da probabilidade da resposta como medida privilegiada nessa investigação, (d) a ênfase no estudo dos efeitos da consequienciação do comportamento, seriam todas decisões anteriores à produção dos dados empíricos da própria pesquisa. Seriam todos pressupostos engendrados por uma filosofia: o Behaviorismo Radical. Da mesma forma, uma análise epistemológica ou cultural dessa perspectiva estaria ligada intrínseca e irremediavelmente aos dados e teorias derivadas de pesquisas empíricas, amplamente realizadas em laboratório, com animais não humanos, sobre condicionamento operante. De fato, um exame epistemológico de cunho skinneriano seria, em grande medida, uma aplicação da noção de operante para entender o comportamento dos cientistas.

Donahoe (1993) identificou duas formas de produção de conhecimento em Análise do Comportamento: a análise experimental e a interpretação. A interpretação seria o uso de conceitos derivados da pesquisa empírica para contextos onde uma investigação dessa natureza seria difícil ou impossível, como seria o caso de uma análise da cultura ou da origem das verbalizações privadas nos seres humanos. O que diferenciaria o exercício de interpretação do analista do comportamento de outras especulações psicológicas, como as de Jung, por exemplo, seria, segundo Donahoe (1993), o amplo lastro experimental que os conceitos/ferra-mentas conceituais teriam. Ao falar da consciência, por exemplo, Skinner irá usar todo o arsenal operante e respondente disponível, tentando identificar pontos de contato entre o comportamento dos organismos no laboratório e o fenômeno da consciência em humanos 
em situação natural. Note-se, então, que o instrumental teórico disponível ao behaviorista radical teria uma gênese empírica.

Em relação ao ramo tecnológico da Análise do Comportamento, a chamada Análise Aplicada do Comportamento, valeria o mesmo raciocínio: o modo de examinar o mundo a ser alterado, que técnicas adotar para mensurar o comportamento alvo, por que adotar medidas comportamentais precisas, por que mudar o comportamento seria a essência desta ferramenta psicológica, e ainda, quais conceitos utilizar nessa leitura do mundo real, seriam todas práticas ligadas ou ao Behaviorismo Radical e/ou a Análise Experimental do Comportamento.

Atualmente, os terapeutas comportamentais discutem longamente em seus encontros de área a necessidade de realizarem um bom diagnóstico comportamental antes de qualquer intervenção planejada propriamente dita. $\mathrm{O}$ instrumento privilegiado a ser usado nessa tarefa seria a identificação de relações funcionais entre padrões de responder e certos aspectos ambientais identificáveis e, preferencialmente, manipuláveis. Note-se, porém, que estabelecer relações funcionais seria a principal tarefa dos pesquisadores no laboratório, e a tarefa nessa configuração particular de investigação experimental foi sugerida no âmbito da filosofia da ciência por autores como Mach e Bridgman (Lopes Jr., 1999).

Em suma, as três subáreas se entrecortam e mutuamente apontam caminhos a serem percorridos e como e por quê chegar até eles. Mas dizer que as três são interligadas seria insuficiente para a compreensão do que estaria interagindo. Tratar-se-á de descrever brevemente o que caracterizaria cada uma.

\section{Parte III: O Behaviorismo Radical (BR)}

O Behaviorismo Radical, ou como aqui sugerido simplesmente BR, foi definido várias vezes por Skinner, como já foi mencionado, como a filosofia de sua Ciência do Comportamento. Isso significa que as razões pelas quais uma ciência dessa natureza seria pretendida e justificada em seus pressupostos e objetivos seria objeto de uma subárea específica dentro desse arranjo mais amplo. Perguntas como "Seria tal ciência possível e necessária?", "Poderia tratar de todos os aspectos da natureza humana?", "Como descrever a origem e a natureza dos eventos psicológicos?" etc, seriam de responsabilidade dessa filosofia. Abib (2001) sugere que o Behaviorismo Radical não seria apenas a filosofia de uma Ciência do Comportamento. Seria para ele sim, uma filosofia da ciência, pois teria pretensões de ir além do seu âmbito estritamente psicológico e teria o que dizer sobre a natureza, produção e legitimação do próprio conhecimento científico. A sugestão faz muito sentido se for levado em conta que Skinner entrou para a Psicologia com grande interesse em epistemologia e inclusive tomou conhecimento da proposta de Watson através da leitura de um texto de Bertrand Russell sobre a noção de significado (Skinner, 1979). Fora o aspecto histórico que explica um pouco da origem da área de investigações estabelecida por Skinner, as áreas de controle de estímulo e de efeitos da conseqüenciação, em especial da conseqüenciação contígua, produzindo os chamados comportamentos "supersticiosos", vêm já sendo exploradas com interesse epistemológico, como em Baum (1994/1999), Barba (2001) e Dawkins (1998/ 2000), por exemplo.

Abib (2001) não pára por aí; amplia ainda mais o alcance dessa filosofia ao afirmar que o Behaviorismo Radical seria uma filosofia do comportamento humano, em todos os seus aspectos. Sendo assim, estaria habilitado a debater temas amplos e centrais na cultura como a linguagem, a política, a ética, a arte e a natureza humana, por exemplo.

Quando Skinner diferencia a sua versão de Behaviorismo, Radical, da defendida por Boring \& Stevens, Metodológico, o que está centralmente em jogo é a concepção de ciência e suas implicações para uma ciência psicológica. Como conciliar uma rigorosa investigação científica nos moldes das ciências naturais com a incorporação de problemas clássicos da filosofia, como a natureza e origem da privacidade humana? Que lugar seria reservado aos eventos ditos "subjetivos", aos quais, por definição, ninguém mais teria acesso direto a não ser o próprio indivíduo? Ao conceber uma forma muito particular de operacionismo, Skinner e o seu Behaviorismo Radical acabaram podendo incorporar os fenômenos subjetivos sem precisar adotar as explicações tradicionais, mentalistas, para eles. Com isso, as proposições comportamentais de Skinner não se afastam dos eventos concretos tradicionais da Psicologia, como foram forçados a fazer os behavioristas metodológicos e seu critério de verdade por consenso público, e dão ao Behaviorismo uma perspectiva mais ampla de possibilidades (Baum, 1999; Matos, 1999; Tourinho, 1999).

\section{Parte IV: A Análise Experimental do Comportamento (AEC)}

A Análise Experimental do Comportamento, ou simplesmente AEC, é a subárea encarregada de conduzir a produção e validação de dados empíricos em uma ciência autônoma do comportamento. Apesar de formalmente ter surgido com os trabalhos de Skinner que culminaram na publicação em 1938 do "The Behavior of Organisms" ("O Comportamento dos Organismos"), Millenson (1967/1975) sugere a existência de uma longa linhagem de pesquisas 
empíricas, que passariam pela tradição fisiológica de investigação do reflexo até autores como Darwin, Romanes, Watson e Thorndike. Parece razoável supor que o conjunto de trabalhos listados e descritos por Millenson (1967/1978) façam parte mais do contexto histórico que permitiu o surgimento de uma Ciência do Comportamento nos moldes skinnerianos e não a disciplina em si mesma. Assim, tratar-se-á a Análise Experimental como elaborada por Skinner (1938/1966).

Iniciar pela decomposição do nome "Análise Experimental do Comportamento" parece ser útil.

O termo "Análise" explicita que o objetivo dessa ciência está estreitamente vinculado a uma tradição reducionista e indutiva, ou seja, acessar inicialmente o todo complexo pela investigação minuciosa de suas partes. Obviamente, trata-se apenas de um primeiro passo na investigação. A finalidade dessa ciência não é separar e manter os aspectos estudados eternamente separados e desconectados em sua simplicidade cômoda, mas pouco realista. Trata-se de uma opção metodológica com fins claros e data de vencimento definida. Avançar gradativamente rumo ao complexo é o objetivo final, e fazer isso significa ampliar o número de variáveis estudadas e entender como se dá a interação entre o maior número possível desses eventos. O comportamento é um sistema complexo e precisa ser compreendido enquanto tal. Há uma esmagadora quantidade de variáveis a se considerar, mas ainda assim é possível identificar regularidades na complexidade. A Meteorologia lida igualmente com um gigantesco e mutante conjunto de variáveis afetando o seu objeto. Uma previsão razoável do clima exige o manuseio de enormes quantidades de informações das mais variadas, da temperatura ambiente à composição química das nuvens, e tudo deve ser atualizado constantemente. Computadores de altíssima capacidade de memória e velocidade no processamento de informações são usados. Um sistema contínuo de alimentação e interpretação de dados é essencial. As regularidades são descobertas, e a previsão se torna cada vez mais precisa. O comportamento humano não exige a adoção de um paradigma diferente de ciência. É preciso sim ampliar o conhecimento das variáveis que afetam o sistema inteiro e a criação de técnicas e tecnologias capazes de alimentar constantemente um banco de informações a ser usado na previsão de eventos comportamentais particulares. O problema da imprevisibilidade do comportamento não é uma questão da natureza supostamente especial do fenômeno, mas dos limites do conhecimento atual sobre ele. O determinismo assumido não é o absoluto, mas sim, o probabilístico (Skinner, 1953/1965; Bacharach, 1965/1975). Mas o percentual de erro não seria gerado por inexplicáveis características intrínsecas ao objeto, como o apelo equivocado ao princípio da incerteza de Heisenberg (para uma crítica aos abusos desse princípio da física nas ciências humanas, ver Marx e Hillix, 1963/1993 e Sokal e Bricmont, 1999). As barreiras estão na pesquisa (método e momento da organização teórica) e não no objeto, e por isso podem ser superadas com trabalho e criatividade.

O termo "Experimental" diz respeito à produção do conhecimento de forma empírica que adota um planejamento de manipulação de variáveis em um contexto controlado e deliberadamente simplificado e artificial. Identificar relações funcionais equivaleria a identificar que variáveis antecedentes e conseqüentes afetariam, e como, a freqüência de uma classe de respostas. O comportamento operante assume um caráter quase onipresente nas pesquisas experimentais realizadas por analistas do comportamento. A relação é tão estreita que Catania e Harnard (1988) definiram o Behaviorismo de Skinner como "Behaviorismo Operante". Note-se que a restrição "experimental" é apenas aparente. Há outras formas legítimas de conduzir uma investigação empírica sobre o fenômeno comportamental, e Skinner (1953/1965) identificou várias dessas alternativas, inclusive pesquisas de campo nas quais a manipulação precisa de variáveis selecionadas previamente não seria possível. A experimentação aqui ganharia um papel de "método ideal" em uma Ciência do Comportamento, mas não teria a ambição de ser o único modo de apreender as regras de funcionamento da ação dos organismos. Note-se, assim, que há amplas possibilidades de pesquisa empírica fora dos limites do laboratório, desde observações sistemáticas do comportamento em ambiente natural na busca de regularidades (mas sem a manipulação de variáveis) até procedimentos de coleta em contextos semi-experimentais, como em certas instituições educacionais e terapêuticas (para uma relação completa das fontes de dados sobre o comportamento, ver Skinner, 1953/1965).

A última fração seria "do Comportamento". Aqui fica explicitado qual o objeto de estudo a ser alvo da "Análise Experimental". O comportamento em si mesmo seria o legítimo objeto a ser examinado e desvendado. Comportamento, por sua vez, seria a interação entre um organismo, fisiologicamente constituído como um equipamento anatomofisiológico, e o seu mundo, histórico e imediato. Os diversos intercâmbios entre o organismo e o seu mundo seriam tratados aqui por "comportamento" ou "ação". Note-se que um intercâmbio desse tipo pode possuir diferentes dimensões que não simplesmente um "movimento" ou um "deslocamento" (como o próprio Skinner sugere algumas vezes. Ver, por exemplo, Skinner, 1938/1966 e 1968b). Na tradição fisiológica, a palavra comportamento foi associada à dimensão observável dos movimentos de partes do corpo, como o "andar 
em direção ao carro", mas o termo pode ter sentidos mais amplos. "Falar" e "pensar" são atividades do organismo em seu intercâmbio com seu contexto, mas não guardam dimensões de "deslocamento". Qual a parte do corpo que "se desloca" dentro de um quadro de referência quando alguém resolve um problema de matemática com o apoio de auto-descrição de regras? Qual o "movimento" em relação a um quadro de referência externo envolvido no "ver" e no "ouvir"? São todas formas de intercâmbio com o mundo, e uma taxonomia dessas diversas atividades talvez pudesse ajudar na elucidação do que seria "comportamento", já que o termo não seria monolítico e exigiria a identificação de seus diversos componentes (para uma discussão mais longa do termo, ver De Rose, 1999, Matos, 1999 e Matos e Tomanari, 2002).

\section{Parte V: A Análise Aplicada do Comportamento (AAC)}

$\mathrm{Na}$ Análise Aplicada do Comportamento, ou simplesmente AAC, estaria o campo de intervenção planejada dos analistas do comportamento. Nela, estariam assentadas as práticas profissionais mais tradicionalmente identificadas como psicológicas, como o trabalho na clínica, escola, saúde pública, organização e onde mais houver comportamento a ser explicado e mudado. Nessas áreas, há uma exigência por resultados e uma relação diferente da acadêmica que, por vezes, torna a produção de conhecimentos metodológica e eticamente delicadas (Luna, 1999). Ainda assim, é possível pensar em gerar problemas de pesquisa (inclusive para as demais subáreas, como a conceitual e a experimental), e, dentro de certos limites, implementar a construção do corpo explicativo de princípios comportamentais pela Análise do Comportamento buscada (Kerbauy, 1999). De fato, essa subárea teria pelo menos duas funções vitais: (1) manter o contato com o mundo real e alimentar os pesquisadores na área com problemas comportamentais do mundo natural e (2) mostrar a relevância social de tais pesquisas e justificar sua manutenção e ampliação da área como um todo. Como uma ciência baconiana, não contemplativa, a Análise do Comportamento tem compromissos de melhoria da vida humana e o seu braço aplicado pode funcionar como um eficiente aferidor das conseqüências práticas prometidas. Além disso, a produção de tecnologia também tem caráter epistemológico, pois, em tese, uma teoria que fosse capaz de descrever o funcionamento de um evento com mais acuidade e qualidade teria melhores condições de produzir alterações mais precisas sobre esses mesmos eventos. A batalha de Skinner contra o Mentalismo, em grande parte das vezes, tomou esse formato e um dos critérios que o autor defendia para avaliar a veracidade maior das asserções feitas pelos analistas do comportamento sobre os fenômenos comportamentais estaria em sua capacidade de gerar uma efetiva tecnologia comportamental (Carvalho Neto, 2001). Note-se, mais uma vez, que as subáreas estariam estreitamente vinculadas, e toda separação teria um caráter didático e artificial. $O$ que não significa que elas funcionem tão azeitadas como poderia sugerir o trabalho de Tourinho (1999), mas simplesmente que o seu futuro, enquanto prática cultural, dependeria exatamente dessa melhoria nas interfaces.

\section{Referências}

Abib, J. A. D. (2001). Arqueologia do behaviorismo radical e o conceito de mente. Em H. J. Guilhardi, M. B. B. P. Madi, P. P. Queiroz \& M. C. Scoz (Orgs.), Sobre comportamento e cognição vol. 7, 20-35. Santo André: ESETec.

Andery, M. A. P. A. (1990). Uma tentativa de (re)construção do mundo: a ciência do comportamento como ferramenta de intervenção. Tese de Doutorado, não publicada, Pontifícia Universidade Católica de São Paulo. São Paulo: São Paulo.

Bachrach, A. J. (1975). Introdução à pesquisa psicológica (4 reimpressão). (G. P. Witter, trad.). São Paulo: EPU. Publicado originalmente em 1965.

Barba, L. (2001). A ciência de Robinson Crusoé: algumas contribuições da filosofia e da ciência do comportamento para a investigação epistemológica. Em Resumos de Comunicações Científicas do X Encontro da Associação Brasileira de Psicoterapia e Medicina Comportamental (p. 24-25). Campinas, 2001.

Baum, W. M. (1999). Compreender o behaviorismo: ciência, comportamento e cultura (M. T. A. Silva, M. A. Matos, G. Y. Tomanari, E. Z. Tourinho, trads.). Porto Alegre: ARTMED. Publicado originalmente em 1994.

Broadbent, D. E. (1972). Comportamento. (R. S. Schnaiderman, trad.). São Paulo: Perspectiva. Publicado originalmente em 1960.

Carvalho Neto, M. B. (2001). B. F. Skinner e as explicações mentalistas para o comportamento: uma análise históricoconceitual (1931-1959). Tese de Doutorado, não Publicada, Instituto de Psicologia. Programa de Pós-Graduação em Psicologia Experimental. Universidade de São Paulo. São Paulo: SP.

Catania, C. A. \& Harnard, S. (1988). The selection of behavior: The operant behaviorism of B. F. Skinner. Cambridge: Cambridge University Press.

Costa, M. N. P. (1997). Considerações acerca do behaviorismo radical, análise do comportamento e análise experimental do comportamento. Caderno de Textos de Psicologia, 2 (1), 7-10.

Dawkins, R. (2000). Desvendando o arco-íris: ciência, ilusão e encantamento. (R. Eichenberg, trad.). São Paulo: Companhia das Letras. Publicado originalmente em 1998.

De Rose, J. C. C. (1999). O que é comportamento? Em R. A. Banaco (Org.), Sobre comportamento e cognição, 1 (p. 79-81) ( $2^{\mathrm{a}}$ ed.). Santo André: Arbytes.

Donahoe, J. W. (1993). The unconventional wisdom of B. F. Skinner: the analysis-interpretation distinction. Journal of the Experimental Analysis of Behavior, 60(2), 453-456.

Heidbreder, E. (1975). Psicologias do século XX. (3 ${ }^{\mathrm{a}}$ ed.) (L. S. Blandy, trad.). São Paulo: Mestre Jou. Publicado originalmente em 1933.

Kerbauy, R. R. (1999). Como fazer pesquisa em clínica? Em R. A. Banaco (Org.), Sobre comportamento e cognição, 1, 338-347. ( $2^{\mathrm{a}}$ ed.) Santo André: Arbytes. 
Lopes Jr., J. (1999). Sobre a incidência do operacionismo na psicologia. Em R. A. Banaco (Org.), Sobre comportamento e cognição, 1 (p. 167-173). (2 ed.) Santo André: Arbytes.

Luna, S. V. (1999). O terapeuta é um cientista? Em R. A. Banaco (Org.), Sobre comportamento e cognição, 1, 305-313. ( $2^{\mathrm{a}}$ ed.) Santo André: Arbytes.

Marcos, M. A. \& Carvalho Neto, M. B. (2001). As contribuições de J. B. Watson para a evolução da propaganda: ensaio histórico e panorama atual de sua influência. Em Resumos de Comunicações Científicas do X Encontro da Associação Brasileira de Psicoterapia e Medicina Comportamental ( $\mathrm{p}$. 110). Campinas, 2001.

Marx, M. H. \& Hillix, W. A. (1993). Sistemas e teorias em psicologia. ( $9^{\mathrm{a}}$ ed.) (A. Cabral, trad.). São Paulo: Cultrix. Publicado originalmente em 1963.

Matos, M. A. \& Tomanari, G. Y. (2002). A análise do comportamento no laboratório didático. São Paulo: Manole.

Matos, M. A. (1999). O behaviorismo metodológico e suas relações com o mentalismo e o behaviorismo radical. Em R. A. Banaco (Org.), Sobre comportamento e cognição, 1 (p. 54-67). Santo André, SP: Arbytes.

Millenson, J. R. (1975). Princípios de análise do comportamento. (A. A. Souza e D. Rezende, trads.). Brasília: Coordenada. Publicado originalmente em 1967.

Skinner, B. F. (1945). Operational analysis of psychological terms. Psychological Review, 52(5), 270-277/291-294.

Skinner, B. F. (1965). Science and human behavior. New York: The Free Press. Publicado originalmente em 1953.

Skinner, B. F. (1966). The behavior of organisms. $7^{\text {a }}$ reimpressão. New York: Applenton-Century-Crofts. Publicado originalmente em 1938.

Skinner, B. F. (1968a). The technology of teaching. New York: Appleton-Century-Crofts.

Skinner, B. F. (1968b). Em R. Evans (Prg.), B. F. Skinner: the man and his ideas. New York: E. P. Dutton \& Co., Inc.

Skinner, B. F. (1971). Walden Two (Twenty-second printing). New York: Collier-Macmillan Company. Publicado originalmente em 1948.

Skinner, B. F. (1972). Cumulative Record ( $3^{\mathrm{a}}$ ed.) New York: Appleton-Century-Crofts.

Skinner, B. F. (1979). The shaping of a behaviorist: part two of an autobiography. New York: Alfred A. Knopf.

Sokal, A. \& Bricmont, J. (1999). Imposturas intelectuais. (M. Altman, trad.). São Paulo/Rio de Janeiro: Record.

Todorov, J. C. (1982). Behaviorismo e análise experimental do comportamento. Caderno de Análise do Comportamento, 3, 1023.

Tourinho, E. Z. (1999). Estudos conceituais na análise do comportamento. Temas em Psicologia da SBP, 7(3), 213-222.

Watson, J. B. (1958). Behaviorism. New York: Norton. Publicado originalmente em 1924.

Watson, J. B. (1965). Psychology as the behaviorist views it. Em R. J. Herrnstein \& E. G. Boring (Orgs.), A source book in the history of psychology. Cambridge: Harvard University Press. Publicado originalmente em 1913. 
Notas:

${ }^{1} \mathrm{O}$ autor agradece as valiosas críticas e sugestões dos pareceristas anônimos, de Carol Vieira e dos professores Tony Nelson, Romariz da Silva Barros e Emmanuel Zagury Tourinho.

${ }^{2}$ Quando duas datas forem apresentadas, a primeira indicará o ano da edição original, e a segunda o ano da edição consultada.

${ }^{3}$ Para outras discussões sobre os termos, ver Costa (1997) e Todorov (1982).

Sobre o autor

Marcus Bentes de Carvalho Neto: Professor Doutor do Departamento de Psicologia Experimental da Universidade Federal do Pará. Endereço para Correspondência: Rua João Canuto, 510. Bairro: Centro. Ananindeua-PA. CEP: 67030-130. E-mail: carvneto@uol.com.br 